\title{
RANCANG BANGUN INSTALASI PENGOLAHAN AIR LIMBAH RUMAH POTONG HEWAN (RPH) AYAM DENGAN PROSES BIOFILTER
}

\author{
Oleh : \\ Nusa Idaman Said dan Satmoko Yudo \\ Kelompok Teknologi Pengelolaan Air bersih dan Limbah Cair, Pusat Pengkajian dan Penerapan \\ Teknologi Lingkungan, BPPT.
}

\begin{abstract}
Abstrak
More than $90 \%$ of Jakarta livestock supply, especially poultry, originated from outside the area. Meanwhile temporary places and slaughterhouse are spread out in some locations in Jakarta area, even most of them located in residences area. Almost all wastewater are not processed but straightly discharged to the sewer or river around the house. These spread chickens slaughterhouse activities caused environmental pollution which is difficult to control.

This paper discussed about the design of wastewater process installation of chickens slaughter by biofilter anaerob-aerob process and test of its process result. Based on the test the removal efficiency of COD, Permanganate, BOD and Total Suspended Solid (TSS) were $86.52 \%, 82.85 \%, 88.79 \%$ and $94.1 \%$ respectively..
\end{abstract}

Keyword : Design, process, wastewater, chicken slaughterhouse, biofilter.

\section{PENDAHULUAN}

\subsection{Latar Belakang Masalah}

Pasokan hewan ternak khususnya unggas/ayam di Jakarta lebih dari $90 \%$ berasal dari wilayah luar DKI Jakarta. Saat ini tempat penampungan sementara dan tempat pemotongannya tersebar di beberapa lokasi di wilayah DKI Jakarta. Bahkan sebagian besar berlokasi di kawasan permukiman. $\mathrm{Di}$ Kotamadya Jakarta Timur sendiri, terdapat 74 buah usaha tempat penampungan ayam (TPA) dengan kapasitas penampungan sekitar 125.000 ekor/hari, dan 572 buah usaha pemotongan ayam dengan kapasitas potong lebih dari 40.000 ekor/hari. Pada umumnya usaha tersebut merupakan usaha skala kecil dengan kapasitas kurang dari 100 ekor/hari/usaha. Usaha ini sebagalian besar dilakukan di rumah-rumah di kawasan padat penduduk. Hampir semua limbah dari usaha tersebut umumnya tidak diolah terlebih dahulu, akan tetapi langsung dibuang di selokan atau sungai di sekitar rumah. Tidak terpusatnya aktivitas pemotongan ayam, mengakibatkan pencemaran lingkungan disekitarnya yang sulit untuk di kontrol.

Permasalahan mulai timbul, setelah masyarakat sekitarnya mengeluhkan terjadinya pencemaran lingkungan yang diakibatkan limbah padat, maupun limbah cair serta bau yang kurang sedap. Limbah yang dihasilkan oleh usaha ini mencapai 150 gram/ekor limbah padat, 1(satu) liter/ekor limbah cair, disamping pencemaran udara dan kebisingan. Dalam setahun diperkirakan akan dihasilkan 2.200 ton limbah padat dan sekitar 14 juta liter limbah cair. Untuk mengatasi masalah pencemaran lingkungan dan pengawasan terhadap kualitas unggas potong di DKI Jakarta, Pemerintah Jakarta Timur melalui Suku Dinas Peternakan Jakarta Timur berupaya melakukan sentralisasi kegiatan penampungan dan pemotongan di kawasan industri PT JIEP di Kelurahan Jatinegara, Kecamatan Cakung. Serta untuk mengatasi pencemaran limbah cairnya telah dibangun instalasi pengolahan air limbah (IPAL) rumah potong hewan tersebut.

\subsection{Tujuan Dan Sasaran}

Tujuan dari kegiatan ini adalah merancang-bangun instalasi pengolahan limbah cair rumah potong hewan khususnya hewan unggas dengan proses bio-filter.

Sedangkan sasaran yang diperoleh adalah diperolehnya teknologi pengolahan limbah cair rumah potong hewan yang dapat mengatasi pencemaran lingkungan.

\subsection{Ruang Lingkup dan Metodologi}

\section{Ruang Lingkup :}

Lingkup kegiatan yang dilakukan secara garis besar adalah sebagai berikut :

- Melakukan survei lokasi untuk mendapatkan data-data awal (misal, kapasitas air limbah yang dikeluarkan). 
- Kondisi fisik kawasan, terutama yang berkaitan dengan aspek penyehatan lingkungan.

- Pengambilan contoh air limbah untuk diperiksa parameter pencemarnya.

- Analisa data untuk pemilihan proses yang akan digunakan.

- Membuat disain teknis (Design Engineering) Instalasi Pengolahan Air Limbah (IPAL) rumah potong hewan (RPH). Kriteria disain dititik beratkan pada aspek teknis, ekonomis dan soial budaya, serta sedapat mungkin menggunakan komponen lokal.

- Membuat IPAL RPH khususnya unggas/ayam.

\section{Metodologi :}

Metodologi kegiatan ini adalah sebagai berikut :

\section{a. Survai Lapangan}

Survai ini dilakukan untuk mengetahui keadaan di lapangan mengenai jumlah ayam yang dipotong, jumlah limbah yang dihasilkan, serta kondisi sosial masyarakatnya.

\section{b. Penentuan Lokasi}

Lokasi unit alat pengolah air limbah harus ditentukan sedemikian rupa agar didapatkan hasil yang memuaskan, baik ditinjau dari segi teknis maupun estetika. Sedapat mungkin lokasi ditentukan agar mengganggu pemukiman masyarakat setempat.

\section{c. Ketersediaan Bahan dan Peralatan}

Bahan dan peralatan yang diperlukan untuk pembangunan unit pengolahan air limbah diharapkan dapat dengan mudah didapat di pasaran, sehingga dapat memberikan kemudahan dalam pengerjaan pembangunan dan biaya konstruksi dapat ditekan serendah mungkin.

\section{d. Rancangan dan Konstruksi}

Disain unit alat pengolah air limbah dirancang berdasarkan jumlah dan kualitas air baku, serta sesuai dengan ketersediaan lahan yang ada. Prototipe alat pengolah air limbah tersebut tersebut akan dirancang dalam bentuk yang kompak agar pemasangan/pembangunan serta operasinya mudah, serta diusahakan menggunakan energi sekecil mungkin.

\section{e. Pembangunan IPAL RPH dan Pengujian Karakteristik Alat}

Setelah alat pengolah air limbah selesai dibangun, dilakukan pengujian karakteristik alat dan pengujian hasil pengolahan terhadap beberapa parameter sesuai dengan standar kualitas limbah rumah potong hewan.

\section{f. Pelatihan Pengopersian Alat}

Sebelum diserahkan kepada calon pengelola, dilakukan pelatihan pengoperasian alat serta cara perawatan alat kepada calon pengelola agar alat dapat beroperasi dengan baik dan terawat.

\section{PROSES PENGolahAN LIMBAH RPH AYAM}

\subsection{Proses Pengolahan Ipal}

Proses pengolahan air limbah rumah potong hewan dengan sistem biofilter anaerobaerob dapat dilihat pada Gambar 1. Seluruh air limbah yang berasal dari kegiatan rumah potong hewan dialirkan melalui saluran pembuang dan dilewatkan melalui saringan kasar (bar screen) untuk menyaring sampah yang berukuran besar seperti sampah bulu hewan, daun, kertas, plastik dll. Setelah melalui screen air limbah dialirkan ke bak pemisah lemak atau minyak. Bak pemisah lemak tersebut berfungsi untuk memisahkan lemak atau minyak yang berasal dari kegiatan pemotongan hewan, serta untuk mengendapkan kotoran pasir, tanah atau senyawa padatan yang tak dapat terurai secara biologis.

Selanjutnya limpasan dari bak pemisah lemak dialirkan ke bak ekualisasi yang berfungsi sebagai bak penampung limbah dan bak kontrol aliran. Air limbah di dalam bak ekualisasi selanjutnya dipompa ke unit IPAL.

Di dalam unit IPAL tersebut, pertama air limbah dialirkan masuk ke bak pengendap awal, untuk mengendapkan partikel lumpur, pasir dan kotoran organik tersuspesi. Selain sebagai bak pengendapan, juga berfungsi sebagai bak pengurai senyawa organik yang berbentuk padatan, sludge digestion (pengurai lumpur) dan penampung lumpur.

Air limpasan dari bak pengendap awal selanjutnya dialirkan ke bak kontaktor anaerob dengan arah aliran dari atas ke bawah, dan dari bawah ke atas. Di dalam bak kontaktor anaerob tersebut diisi dengan media dari bahan plastik tipe sarang tawon. Jumlah bak kontaktor anaerob terdiri dari dua buah ruangan. Penguraian zat-zat organik yang ada dalam air limbah dilakukan oleh bakteri anaerobik atau facultatif aerobik. Setelah beberapa hari operasi, pada permukaan media filter akan tumbuh lapisan film mikro-organisme. Mikro-organisme inilah yang akan menguraikan zat organik yang belum sempat terurai pada bak pengendap.

Air limpasan dari bak kontaktor anaerob dialirkan ke bak kontaktor aerob. Di dalam bak kontaktor aerob ini diisi dengan media dari bahan plastik tipe sarang tawon, sambil diaerasi atau dihembus dengan udara sehingga mikro organisme yang ada akan menguraikan zat 
organik yang ada dalam air limbah serta tumbuh dan menempel pada permukaan media. Dengan demikian air limbah akan kontak dengan mikroorganisme yang tersuspensi dalam air maupun yang menempel pada permukaan media yang mana hal tersebut dapat meningkatkan efisiensi penguraian zat organik, deterjen serta mempercepat proses nitrifikasi, sehingga efisiensi penghilangan ammonia menjadi lebih besar. Proses ini sering di namakan Aerasi Kontak (Contact Aeration).

Dari bak aerasi, air dialirkan ke bak pengendap akhir. Di dalam bak ini lumpur aktif yang mengandung massa mikro-organisme diendapkan dan dipompa kembali ke bagian inlet bak aerasi dengan pompa sirkulasi lumpur.

Sedangkan air limpasan (over flow) dialirkan ke bak khlorinasi. Di dalam bak kontaktor khlor ini air limbah dikontakkan dengan senyawa khlor untuk membunuh microorganisme patogen. Air olahan, yakni air yang keluar setelah proses khlorinasi dapat langsung dibuang ke sungai atau saluran umum. Dengan kombinasi proses anaerob dan aerob tersebut selain dapat menurunkan zat organik (BOD, COD), ammonia, padatan tersuspensi (SS), phospat dan lainnya. Diagram proses pengolahan air limbah rumah potong hewan dengan proses biofilter anaerob-aerob dapat dilihat pada Gambar 2.

Proses dengan Biofilter "Anaerob-Aerob" ini mempunyai beberapa keuntungan yakni :

\section{I.2 Keunggulan Biofilter Anaerob-Aerob}

Pengolahan air limbah dengan proses biofilm Anaerob-Aerob mempunyai beberapa keunggulan antara lain :

\section{- Pengoperasiannya mudah}

Di dalam proses pengolahan air limbah dengan sistem biofilm, tanpa dilakukan sirkulasi lumpur, tidak terjadi masalah "bulking" seperti pada proses lumpur aktif (Activated sludge process). Oleh karena itu pengelolaaanya sangat mudah.

\section{- Lumpur yang dihasilkan sedikit}

Dibandingkan dengan proses lumpur aktif, lumpur yang dihasilkan pada proses biofilm relatif lebih kecil. Di dalam proses lumpur aktif antara 30 - $60 \%$ dari BOD yang dihilangkan (removal BOD) diubah menjadi lumpur aktif (biomasa) sedangkan pada proses biofilm hanya sekitar 10-30 \%. Hal ini disebabkan karena pada proses biofilm rantai makanan lebih panjang dan melibatkan aktifitas mikroorganisme dengan orde yang lebih tinggi dibandingkan pada proses lumpur aktif.

- Dapat digunakan untuk pengolahan air limbah dengan konsentrasi zat Organik rendah maupun tinggi.

Oleh karena di dalam proses pengolahan air limbah dengan sistem biofilm mikroorganisme atau mikroba melekat pada permukaan medium penyangga maka pengontrolan terhadap mikroorganisme atau mikroba lebih mudah. Proses biofilm tersebut cocok digunakan untuk mengolah air limbah dengan konsentrasi rendah maupun konsentrasi tinggi.

- Tahan terhadap fluktuasi jumlah air limbah maupun fluktuasi konsentrasi.

- Pengaruh penurunan suhu terhadap efisiensi pengolahan kecil.

Jika suhu air limbah turun maka aktifitas mikroorganisme juga berkurang, tetapi oleh karena di dalam proses biofilm substrat maupun enzim dapat terdifusi sampai ke bagian dalam lapisan biofilm dan juga lapisan biofilm bertambah tebal maka pengaruh penurunan suhu (suhu rendah) tidak begitu besar.

- Adanya air buangan yang melalui media kerikil yang terdapat pada biofilter mengakibatkan timbulnya lapisan lendir yang menyelimuti kerikil atau yang disebut juga biological film. Air limbah yang masih mengandung zat organik yang belum teruraikan pada bak pengendap bila melalui lapisan lendir ini akan mengalami proses penguraian secara biologis. Efisiensi biofilter tergantung dari luas kontak antara air limbah dengan mikro-organisme yang menempel pada permukaan media filter tersebut. Makin luas bidang kontaknya maka efisiensi penurunan konsentrasi zat organiknya (BOD) makin besar. Selain menghilangkan atau mengurangi konsentrasi BOD dan COD, cara ini dapat juga mengurangi konsentrasi padatan tersuspensi atau suspended solids (SS) ammonium dan posphor.

Beberapa keunggulan proses pengolahan air limbah dengan biofilter anaerb-aerob yang lain antara lain yakni :

- Biaya operasinya rendah.

- Dibandingkan dengan proses lumpur aktif, Lumpur yang dihasilkan relatif sedikit.

- Dapat menghilangkan nitrogen dan phospor yang dapat menyebabkan euthropikasi. 
- Energi untuk suplai udara aerasi relatif kecil.

- Dapat digunakan untuk air limbah dengan beban BOD yang cukup besar.

- Dapat menghilangan padatan tersuspensi (SS) dengan baik.

\section{DISAIN TEKNIS IPAL}

Kapasitas Rencana $=400 \mathrm{M}^{3}$ per hari

BOD Masuk = $2000 \mathrm{mg} / \mathrm{lt}$.

SS Masuk $=500 \mathrm{mg} / \mathrm{lt}$

BOD keluar $=50 \mathrm{mg} / \mathrm{lt}$

SS keluar $=50 \mathrm{mg} / \mathrm{lt}$

\section{1) Disain Bak Pemisah Lemak/Minyak}

Bak pemisah lemak atau grease removal yang direncanakan adalah tipe gravitasi sederhana. Bak terdiri dari dua buah ruangan yang dilengkapi dengan bar screen pada bagian inletnya.

Kriteria perencanaan :

Retention Time $= \pm 30$ menit.

Dimensi Bak :

$\begin{array}{ll}\text { Panjang } & : 4 \mathrm{~m} \\ \text { Lebar } & : 1,5 \mathrm{~m} \\ \text { kedalaman air } & : 1,5 \mathrm{~m} \\ \text { Ruang Bebas } & : 0,3-0,5 \mathrm{~m}\end{array}$

Disain bak pemisah lemak dapai dilihat pada Gambar 3

\section{2) Bak Ekualisasi}

Waktu Tinggal $(\mathrm{T})=6$ jam

Dimensi :

$\begin{array}{ll}\text { Lebar } & : 5,0 \mathrm{~m} \\ \text { Panjang } & : 8,0 \mathrm{~m} \\ \text { Kedalaman efektif } & : 2,5 \mathrm{~m} \\ \text { Tinggi Ruang Bebas } & : 0.5 \mathrm{~m}\end{array}$

3) Bak Pengendapan Awal

$\begin{array}{ll}\text { BOD Masuk } & : 2000 \mathrm{mg} / \mathrm{l} \\ \text { BOD Keluar } & : 1200 \mathrm{mg} / \mathrm{l}\end{array}$

Efisiensi : $40 \%$

- Dimensi :

Lebar

$: 7,0 \mathrm{~m}$

Panjang

$4,0 \mathrm{~m}$

Kedalaman air efektif

$: 2,5 \mathrm{~m}$

Tinggi ruang bebas

$: 0,5 \mathrm{~m}$

(disesuaikan dengan kondisi lapangan).

- Waktu Tinggal (Retention Time) rata-rata : 4,2 Jam
- Waktu tinggal pada saat beban puncak : 2,1 Jam (asumsi jumlah limbah $2 x$ jumlah ratarata).

- Beban permukaan (surface loading) rata-rata : $14,3 \mathrm{~m}^{3} / \mathrm{m}^{2}$.hari

- Beban permukaan pada saat puncak : 28,6 $\mathrm{m}^{3} / \mathrm{m}^{2}$.hari.

- Standar :

Beban permukaan : $20-50 \mathrm{~m}^{3} / \mathrm{m}^{2}$.hari. (JWWA)

4) Biofilter Anaerob

$\begin{array}{ll}\text { BOD Masuk } & : 1200 \mathrm{mg} / \mathrm{l} \\ \text { Efisiensi } & : 80 \% \\ \text { BOD Keluar } & : 240 \mathrm{mg} / \mathrm{l}\end{array}$

Debit Limbah $\quad: 400 \mathrm{~m}^{3} /$ hari

- Dimensi :

$\begin{array}{ll}\text { Lebar } & : 7,0 \mathrm{~m} \\ \text { Panjang } & : 4,5 \mathrm{~m} \\ \text { Kedalaman air efektif } & : 2,5 \mathrm{~m} \\ \text { Tinggi ruang bebas } & : 0,5 \mathrm{~m} \\ \text { Jumlah ruang } & : 2 \text { buah }\end{array}$

Waktu tinggal total rata2 :9,45 jam

Waktu tinggal total pada saat beban puncak : 4,7 jam

- $\quad$ Tinggi ruang lumpur : 0,4 m

- $\quad$ Tinggi Bed media pembiakan mikroba : 1,8 $\mathrm{m}$

- Tinggi air di atas bed media : $20 \mathrm{~cm}$

- Volume total media pada biofilter anaerob : $113,4 \mathrm{~m}^{3}$.

- $\quad$ BOD Loading : 4,23 Kg BOD $/ \mathrm{m}^{3}$.hari.

Standard high rate trickling filter : $0,4-4,7 \mathrm{~kg}$ $\mathrm{BOD} / \mathrm{m}^{2}$.hari.

Jika media yang dipakai mempunyai luas spesifik $\pm 225 \mathrm{~m}^{2} / \mathrm{m}^{3}$

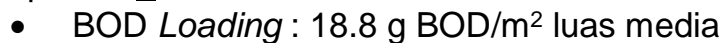
per hari.

5) Biofilter Aerob

$\begin{array}{ll}\text { BOD Masuk } & : 240 \mathrm{mg} / \mathrm{l} \\ \text { Efisiensi } & : 80 \% \\ \text { BOD Keluar } & : 50 \mathrm{mg} / \mathrm{l}\end{array}$

Debit Limbah $\quad: 400 \mathrm{~m}^{3} /$ hari

- Dimensi total :

$\begin{array}{ll}\text { Lebar } & : 7,0 \mathrm{~m} \\ \text { Panjang } & : 7,5 \mathrm{~m}\end{array}$

Kedalaman air efektif : $2,5 \mathrm{~m}$

Tinggi ruang bebas : $0,5 \mathrm{~m}$

- Jumlah Ruang : 2 buah, Ruang I untuk aerasi dan Ruang II untuk biofilter Aerob.

Dimensi Ruang aerasi :

7,0m X 2,5m X 2,5m (efektif)

Dimensi Ruang Biofilter Aerob :

$7 m \times 5 m \times 2,5 m$ (efektif) 
- Waktu tinggal total rata-rata : \pm 8 jam

- Tinggi ruang lumpur $: 0,4 \mathrm{~m}$

- Tinggi Bed media pembiakan mikroba : 1,8 $\mathrm{m}$

- Tinggi air di atas bed media $=20 \mathrm{~cm}$

- Volume total media pada biofilter aerob : 63 $\mathrm{m}^{3}$.

- BOD Loading : 1,52 Kg BOD/m³.hari.

Standard igh rate trickling filter:

$0,4-4,7 \mathrm{~kg} \mathrm{BOD} / \mathrm{m}^{2}$.hari.

Jika media yang dipakai mempunyai luas spesifik $\pm 225 \mathrm{~m}^{2} / \mathrm{m}^{3}$

- $\mathrm{BOD}$ Loading $=6,7 \mathrm{~g} \mathrm{BOD} / \mathrm{m}^{2}$ luas media per hari.

\section{6) Bak Pengendap Akhir}

- Dimensi :

$\begin{array}{ll}\text { Lebar } & : 7,0 \mathrm{~m} \\ \text { Panjang } & : 4,0 \mathrm{~m} \\ \text { Kedalaman air efektif } & : 2,5 \mathrm{~m} \\ \text { Tinggi ruang bebas } & : 0,5 \mathrm{~m}\end{array}$
(disesuaikan dengan kondisi lapangan).

- Waktu Tinggal (Retention Time) rata-rata : 4,2 Jam

- Waktu tinggal pada saat beban puncak : 2,1 Jam ( asumsi jumlah limbah $2 \times$ jumlah ratarata).

- Beban permukaan (surface loading) rata-rata : $14,3 \mathrm{~m}^{3} / \mathrm{m}^{2}$.hari

- Beban permukaan pada saat puncak : 28,6 $\mathrm{m}^{3} / \mathrm{m}^{2}$.hari.

- Standar : Beban permukaan : $20-50 \mathrm{~m}^{3} / \mathrm{m}^{2}$.hari. (JWWA)

\section{7) Media Pembiakan Mikroba}

$\begin{array}{ll}\text { Material } & : \text { PVC sheet } \\ \text { Ketebalan } & : 0,15-0,23 \mathrm{~mm} \\ \text { Luas Kontak Spesifik } & : 200-226 \mathrm{~m}^{2} / \mathrm{m}^{3} \\ \text { Diameter lubang } & : 2 \mathrm{~cm} \times 2 \mathrm{~cm} \\ \text { Warna } & : \text { hitam } / \text { transparan. } \\ \text { Berat Spesifik } & : 30-35 \mathrm{~kg} / \mathrm{m}^{3} \\ \text { Porositas Rongga } & : 0,98\end{array}$

\section{8) Pompa Air Limbah}

A. Pompa Utama :

\begin{tabular}{ll} 
Kapasitas & $: 400 \mathrm{M}^{3} / \mathrm{hari}$ \\
& $(280$ liter/menit) \\
Tipe & $:$ Pompa Celup \\
Total Head & $: 9$ meter \\
Jumlah & $: 2$ buah \\
Listrik & $: 500$ watt, 220 volt \\
\multicolumn{1}{c}{} \\
B. Pompa Cadangan : \\
Kapasitas & $: 200 \mathrm{M}$ 3/hari \\
& $(140$ liter/menit) \\
Tipe & $:$ Pompa Celup (Nocchi \\
& BIOX $375 \mathrm{~A})$ \\
Total Head & $: 9$ meter \\
Jumlah & $: 1$ buah
\end{tabular}

Listrik

: 375 watt, 220 volt

$\begin{array}{ll}\text { 9) Pompa Air Sirkulasi } \\ \text { Kapasitas } & : 200 \mathrm{M} 3 / \text { hari } \\ & \text { (140 liter/menit) } \\ \text { Tipe } & : \text { Pompa Celup } \\ & \text { (Nocchi BIOX 375 A) } \\ \text { Total Head } & : 9 \text { meter } \\ \text { Jumlah } & : 2 \text { buah } \\ \text { Listrik } & : 375 \text { watt, 220 volt }\end{array}$

10) Blower Udara

Kebutuhan Udara

Kapasitas Tiap Blower

Total Head

Tipe

Listrik

Jumlah

\section{: $2,8 \mathrm{~m}^{3} /$ menit \\ $: 1,0 \mathrm{~m}^{3} /$ menit \\ : $2500 \mathrm{~mm}$ air \\ : RING bLOWER \\ : 1200 watt, 220 volt.}

: 3 unit

\section{1) Media Biofilter}

Media biofilter yang digunakan untuk pengolahan air limbah tersebut adalah media dari bahan plastik PVC, tipe sarang tawon.

Jumlah total media yang dibutuhkan = $113,4 m^{3}+63 m^{3}=176,4 m^{3}$

Bentuk media biofilter serta spesifikasinya dapat dilihat pada Tabel 1.

Tabel 1 : Spesifikasi Media Biofilter Tipe Sarang Tawon

\begin{tabular}{|c|c|}
\hline Tipe & : $\quad$ Sarang Tawon, cross flow. \\
\hline Material & : PVC \\
\hline Ukuran Modul & $: 30^{\mathrm{cm}} \times 25^{\mathrm{cm}} \times 30^{\mathrm{cm}}$ \\
\hline Ukuran Lubang & $: 2 \mathrm{~cm} \times 2 \mathrm{~cm}$ \\
\hline Ketebalan & $: 0,5 \mathrm{~mm}$ \\
\hline Luas Spesifik & $: 150-225 \mathrm{~m}^{2} / \mathrm{m}^{3}$ \\
\hline Berat & $: \quad 30-35 \mathrm{~kg} / \mathrm{m}^{3}$ \\
\hline Porositas Ronga & $: 0,98$ \\
\hline Warna & $\begin{array}{l}\text { bening transparan atau } \\
\text { Hitam }\end{array}$ \\
\hline
\end{tabular}

Dari hasil perhitungan disain tersebut di atas dihasilkan disain konstruksi IPAL sebagai berikut.

- Bak Pemisah Lemak dan Bak Ekualisasi dapat dilihat pada Gambar 3 . 
- Disain Reaktor Pengolahan Air Limbah Rumah Potong Hewan (Ayam) dapat dilihat pada Gambar 4.

- Gambar potongan IPAL Rumah Potong Hewan (Ayam) dapat dilihat pada Gambar 5.

- Konstruksi IPAL Rumah Potong Hewan (Ayam) kapasitas $400 \mathrm{~m}^{3}$ per hari dapat dilihat pada Gambar 6.

\section{UJI COBA IPAL}

Dari hasil uji coba IPAL rumah potong ayam dengan proses biofilter anaerob-aerob yang dibangun di tempat penampungan dan pemotongan ayam di kawasan industri PT JIEP di Kelurahan Jatinegara, Kecamatan Cakung. Dari hasil pemeriksaan beberapa parameter kualitas air sebelum dan sesudah pengolahan didapatkan hasil sebagai berikut. Konsentrasi COD air limbah sebelum pengolahan $558 \mathrm{mg} / \mathrm{l}$, setelah pengolahan turun menjadi $75,24 \mathrm{mg} / \mathrm{l}$, dengan efisiensi penurunan sebesar 86, $52 \%$. Konsentrasi angka permanganat di dalam air limbah yang masuk $304 \mathrm{mg} / \mathrm{l}$ setelah pengolahan turun menjadi $51,13 \mathrm{mg} / \mathrm{l}$, dengan efisiensi penurunan $82,85 \%$. Konsentrasi BOD di dalam air limbah yang masuk $261 \mathrm{mg} / \mathrm{l}$ dan sesudah pengolahan turun menjadi 29, $26 \mathrm{mg} / \mathrm{l}$ dengan efisiensi penurunan $88,79 \%$. Untuk total padatan tersuspensi (TSS), konsentrasi di dalam air limbah yang masuk $373 \mathrm{mg} / \mathrm{l}$ dan sesudah pengolahan turun menjadi $22,0 \mathrm{mg} / \mathrm{l}$ dengan efisiensi penurunan sebesar 94,10 \%. Sedangkan $\mathrm{pH}$ air limbah yang masuk 6,98, sesudah pengolahan naik menjadi 7,31. Hasil selengkapnya dapat dilihat pada Tabel 2.

Tabel 2 : Hasil pengukuran parameter air limbah sebelum dan sesudah pengolahan (pada tanggal 17 April 2004)

\begin{tabular}{|c|l|c|c|c|}
\hline No & Parameter & $\begin{array}{c}\text { Influent } \\
(\mathbf{m g} / \mathbf{l})\end{array}$ & $\begin{array}{c}\text { Olahan } \\
(\mathbf{m g} / \mathbf{l})\end{array}$ & $\begin{array}{c}\text { Efisiensi } \\
(\%)\end{array}$ \\
\hline 1 & COD & 558 & 75,24 & 86,52 \\
\hline 2 & $\begin{array}{l}\text { (Angka } \\
\left.\mathrm{KMnO}_{4}\right)\end{array}$ & 304 & 52,13 & 82,85 \\
\hline 3 & $\mathrm{BOD}_{5}$ & 261 & 29,26 & 88,79 \\
\hline 4 & TSS & 373 & 22,0 & 94,10 \\
\hline 5 & pH & 6,98 & 7,31 & - \\
\hline
\end{tabular}

Sumber : Hasil analisa Lab.

Hasil tersebut di atas jika dibandingkan dengan baku mutu limbah cair industri, perusahaan atau badan sesuai dengan keputusan Gubernur DKI Jakarta No. 582 tahun 1995 sudah memenuhi syarat. Standar baku mutu limbah cair industri berdasarkan Surat Keputusan Gubernur tersebut yakni TSS $100 \mathrm{mg} / \mathrm{l}$, COD $100 \mathrm{mg} / \mathrm{l}$, angka permanganat $85 \mathrm{mg} / \mathrm{l}$ dan BOD $75 \mathrm{mg} / \mathrm{l}$.

\section{PENUTUP}

Dari hasil uraian tersebut di atas dapat dilihat bahwa pengolahan air limbah rumah potong ayam dengan proses biofilter anaerobaerob tercelup dapat dihasilkan kualitas yang cukup baik dan sudah memenuhi syarat sesuai dengan standar baku mutu air limbah industri.

Proses pengolahan air limbah dengan biofilter anaerob-aerob mempunyai beberapa keunggulan yang lain antara lain yakni biaya operasinya rendah, dibandingkan dengan proses lumpur aktif, Lumpur yang dihasilkan relatif sedikit, kebutuhan energi untuk aerasi relatif kecil karena menggunakan kombinasi proses anaerob-aerob, dapat digunakan untuk air limbah dengan beban organik yang cukup besar, serta dapat menghilangan padatan tersuspensi (SS) dengan baik.

\section{DAFTAR PUSTAKA}

1. -----, "Dinas Peternakan Perikanan Dan Kelautan, Provinsi DKI Jakarta, Tempat Penampungan ayam Di Wilayah Jakarta Timur", http://www.inovasipemda.com/isi\%20proyek/ info/data\%20substansi/DKI/KotaJaktim.htm

2. ----, "Gesuidou Shissetsu Sekkei Shisin to Kaisetsu “, Nihon Gesuidou Kyoukai, 1984.

3. Fair, Gordon Maskew et.al., " Elements Of Water Supply And Waste Water Disposal", John Willey And Sons Inc., 1971.

4. Gouda T., "Suisitsu Kougaku - Ouyouben", Maruzen kabushiki Kaisha, Tokyo, 1979.

5. Hikami, Sumiko., "Shinseki rosohou ni yoru mizu shouri gijutsu (Water Treatment with Submerged Filter)", Kougyou Yousui No.411, 12,1992.

6. Metcalf And Eddy, "Waste Water Engineering", Mc Graw Hill 1978.

7. Viessman W, JR., Hamer M.J., "Water Supply And Polution Control“", Harper \& Row, New York,1985. 


\section{LAMPIRAN :}

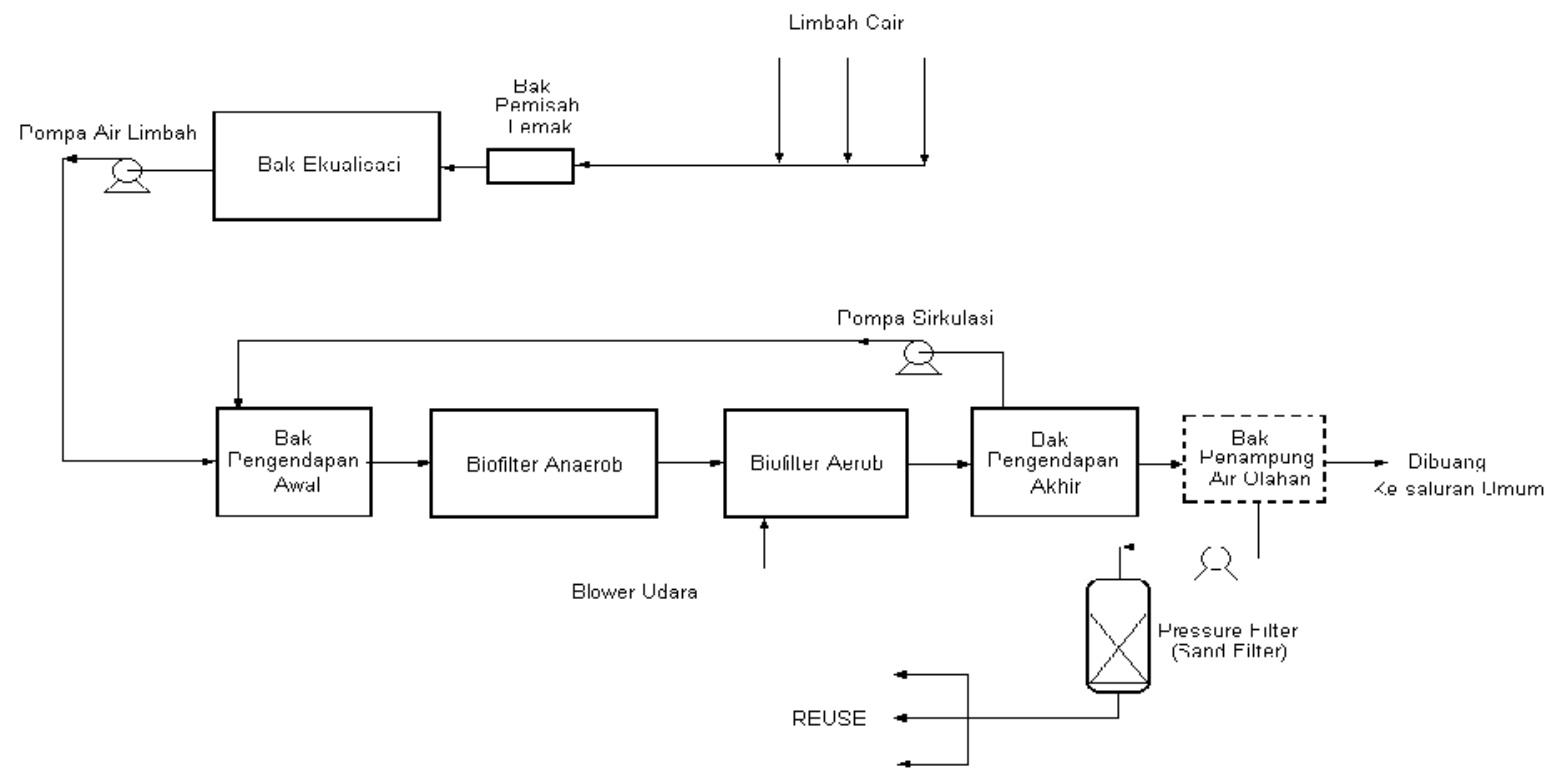

Gambar 1 : Diagram Alir pengolahan air limbah RPH dengan proses biofilter anaerob-aerob.

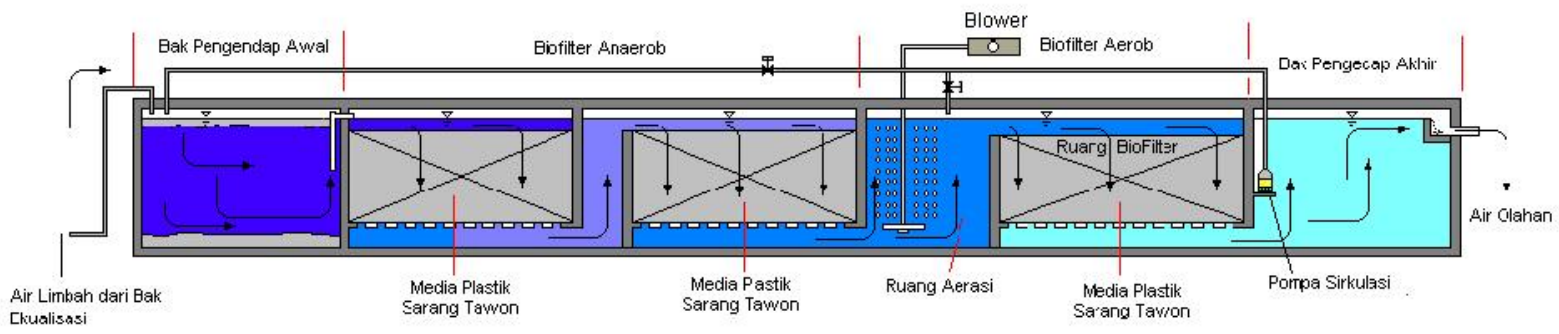

Gambar 2 : Diagram proses pengolahan air limbah rumah potong hewan dengan proses biofilter anaerob-aerob .

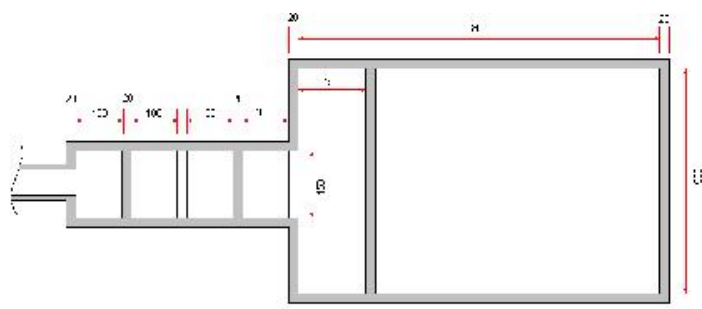

Tampak Atas

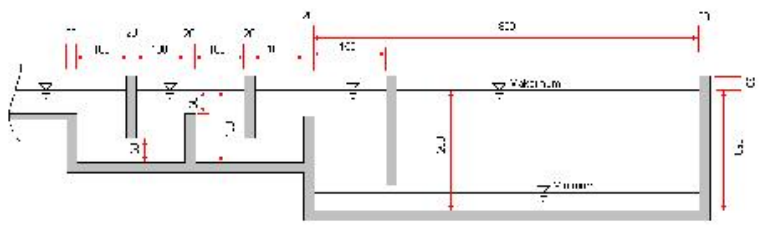

Potongan Melintang

Gambar 3 : Bak Pemisah Lemak dan Bak Ekualisasi 


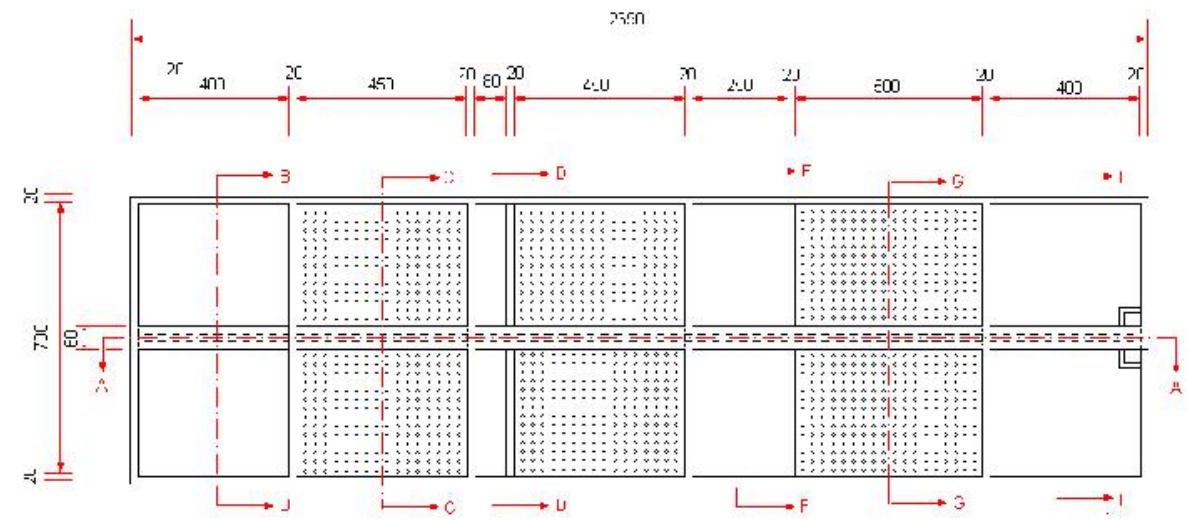

Tampak Atas

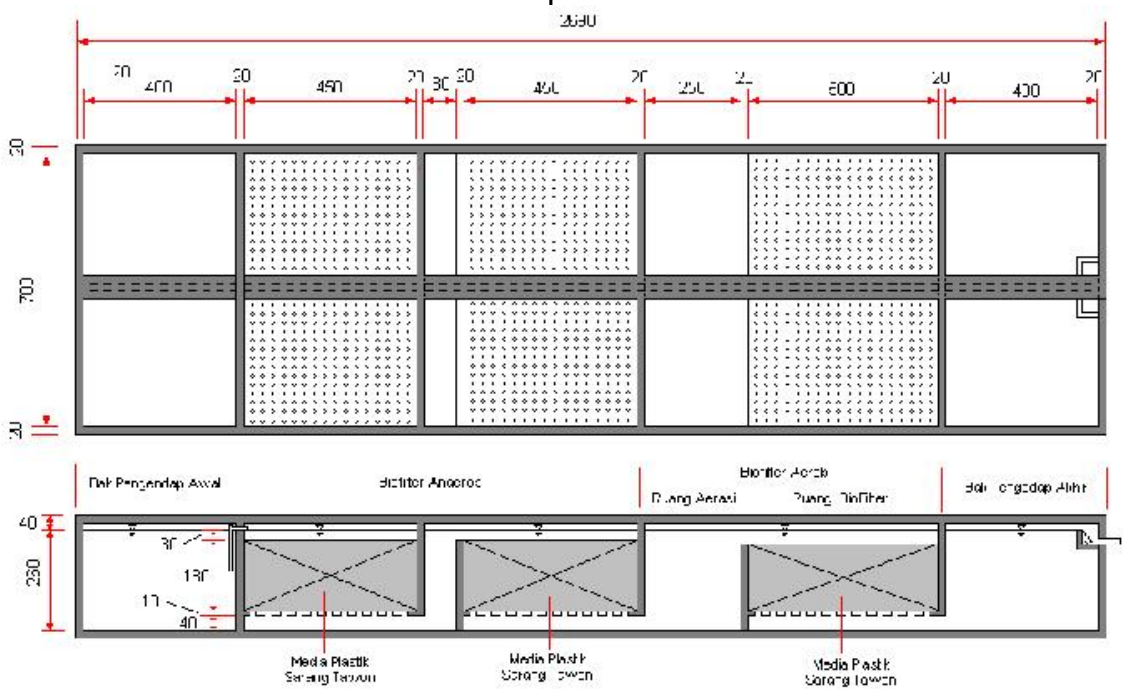

Potongan A - A

Gambar 4 : Disain Reaktor Pengolahan Air Limbah Rumah Potong Hewan (Ayam)
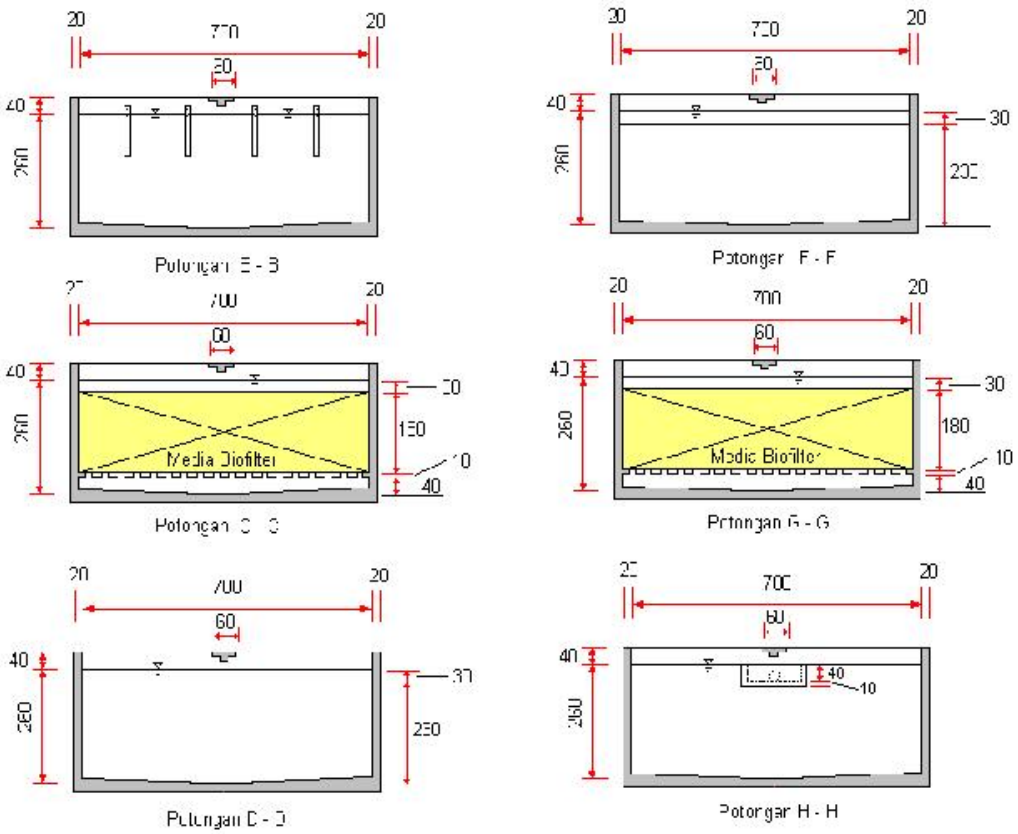

Gambar 5 : Gambar potongan IPAL Rumah Potong Hewan (Ayam) 

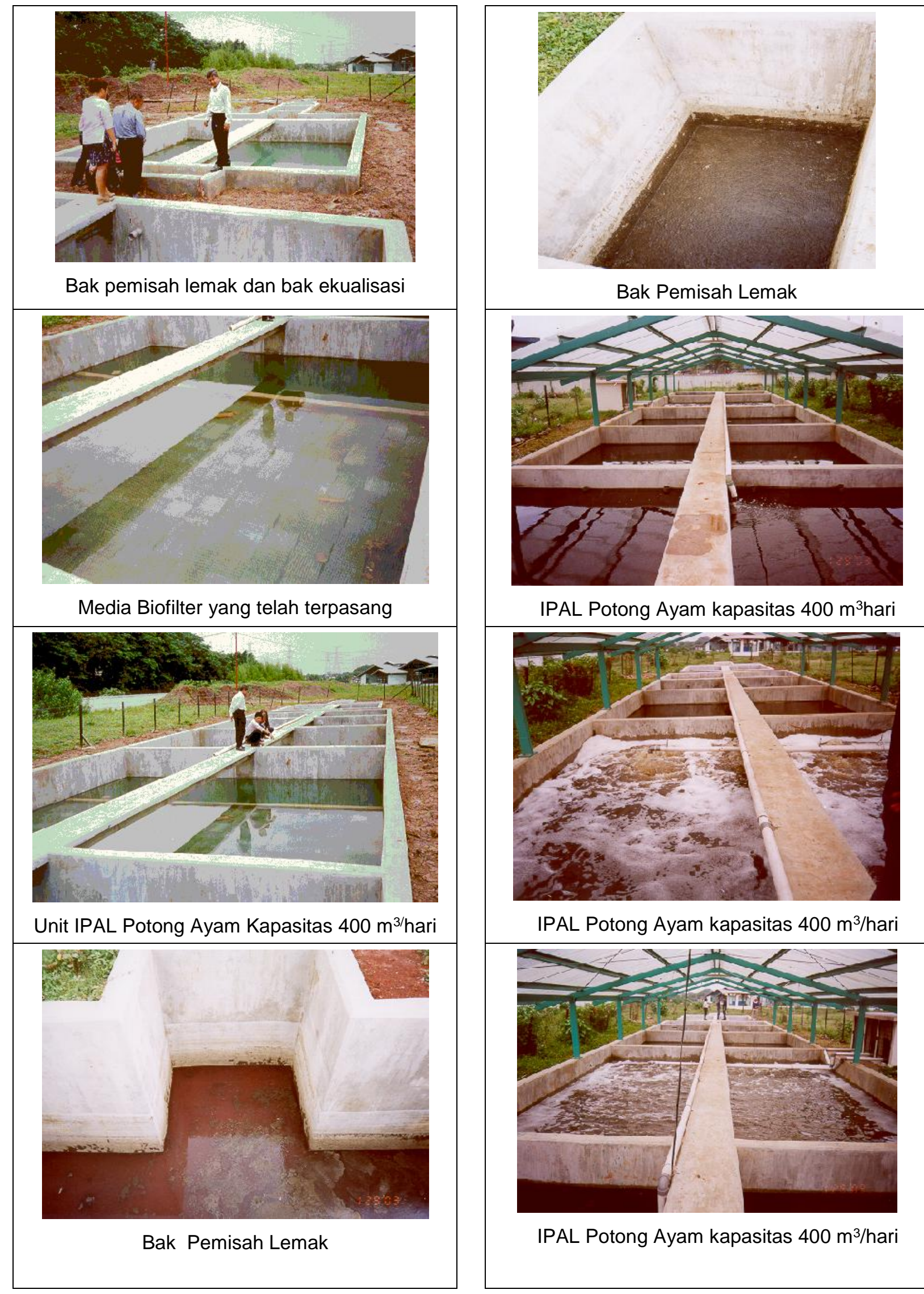

IPAL Potong Ayam kapasitas $400 \mathrm{~m}^{3}$ hari

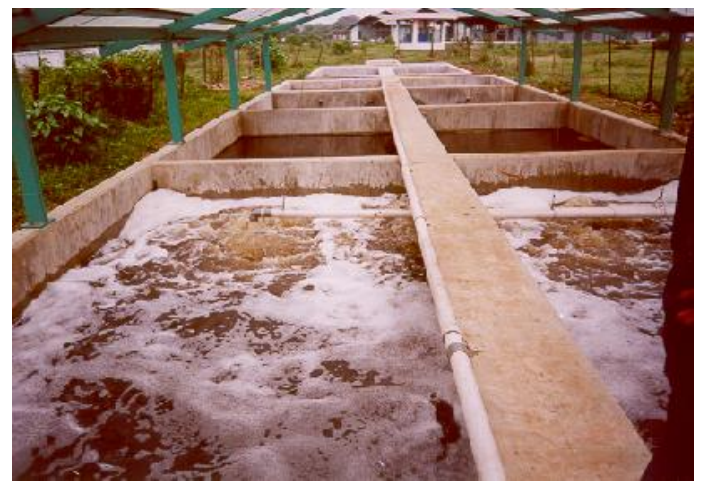

IPAL Potong Ayam kapasitas 400 m³/hari

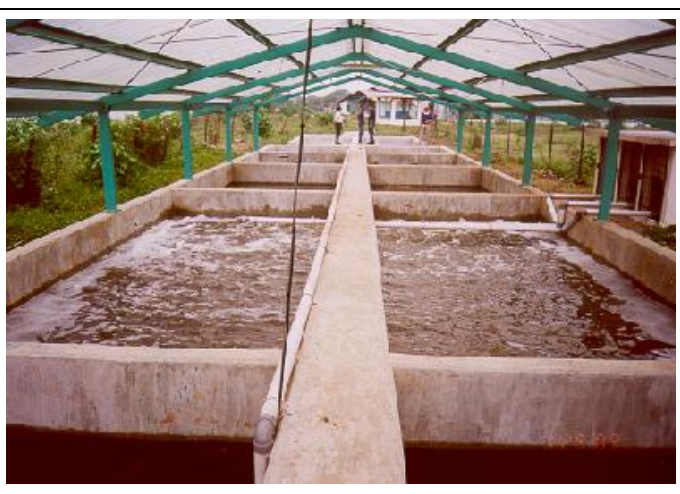

IPAL Potong Ayam kapasitas 400 m³/hari

Gambar 6 : Konstruksi IPAL Rumah Potong Hewan (Ayam) kapasitas $400 \mathrm{~m}^{3}$ per hari. 